\title{
Treatment Outcome and Prognostic Factors of Anaplastic Thyroid Carcinoma: A Single Institution Experience in Egypt
}

\author{
Dina R. D. Ibrahim ${ }^{1}$, Anas M. Askoura ${ }^{2}$ \\ ${ }^{1}$ Clinical Oncology department, Faculty of Medicine, Ain-Shams University, Cairo, Egypt; ${ }^{2}$ Ear, \\ Nose and Throat Department, Faculty of Medicine, Ain-Shams University, Cairo, Egypt
}

Introduction: Anaplastic thyroid carcinoma (ATC) is a rare lethal malignancy. It is one of the most aggressive human malignancies with limited progress in finding effective therapies.

Aim: We aimed to study the treatment outcome and prognostic factors of ATC patients treated at our institution.

Methods: We retrospectively analyzed charts of 30 ATC patients, treated at the Clinical Oncology Department, AinShams University from 2006 to 2017. The clinical characteristics and factors affecting survival were studied. Kaplan-Meier survival curve was used to analyze the overall survival (OS) of the patients.

Results: The median age of patients was 60 years and males represented $63 \%$ of them. Almost half of patients (47\%) had stage IVA disease. Equal number of patients received combined modality treatment versus single modality treatment $(37 \%$ each). The median OS was 3 months (95\% Confidence interval: 1.429-4.571). Variables associated with significantly better OS in univariate analysis included male sex $(p=0.04)$, stage IVA disease $(p=0.012)$, surgical treatment $(p=0.034)$, radiotherapy $(p=0.003)$, and combined modality treatment $(p=0.005)$. However, only female sex was identified as significant poor prognostic variable of OS $(p=0.043)$ by multivariate analysis.

Conclusion: Our results of treatment outcome and prognosis of ATC agree with most of the literature. Multimodality treatment is currently the standard of care. While still there is no successful treatment of this rapidly fatal disease, exploration of novel therapies and approaches are warranted to help improve the outcome.

Keywords: Anaplastic thyroid carcinoma, treatment outcome, multimodal treatment, prognosis.

Corresponding Author: Dina R. Ibrahim, MD, Clinical Oncology department, Faculty of Medicine, Ain-Shams University, Cairo, Egypt. Email: dibrahi1@gmail.com

Submitted: 26-October-2017, Revised: 5-December-2017, Accepted: 15-Decebmer-2017, Published online: 8-January-2018

\section{INTRODUCTION}

Anaplastic thyroid cancer (ATC) is the least common but most aggressive and lethal type of thyroid cancer. It accounts for around 0.6 to $9.8 \%$ of all thyroid malignancies globally but causes up to $40 \%$ of thyroid cancer mortality ${ }^{1-3}$. The annual incidence of ATC is about 1-2 cases per million ${ }^{2,4,5}$. Patients are usually in their $6^{\text {th }}-7^{\text {th }}$ decade of life ${ }^{1,6}$. The etiology is unclear, however in up to $80 \%$ of patients ATC arises on top of a simultaneous or immediately prior thyroid disease, such as benign long standing goiter or well differentiated thyroid carcinomas ${ }^{2,7}$. ATC has an extremely poor response to treatment. The median survival time of ATC is about 5 months and less than $20 \%$ of patients survive 1 year after diagnosis ${ }^{7}$.

Anaplastic thyroid cancer typically has multiple genomic gains and deletions in many chromosomal regions leading to multistep dedifferentiation of thyroid cancers and development and progression of ATC ${ }^{8,9}$. Early events are mutations of the BRAF and $R A S$ oncogenes in $25 \%$ and $28 \%$ respectively. Late genetic events include TP53 which is the most common mutation in ATC, PIK3CA and PTEN gene mutations are commonly found in differentiated thyroid cancers indicating that such mutations may be early steps in cancer formation $5,10,11$.
Anaplastic thyroid cancer should be treated as a medical emergency due to its aggressive nature ${ }^{12}$. By definition ATC is a stage IV disease which is subdivided into $\mathrm{A}, \mathrm{B}, \mathrm{C}$ according to local and distant metastases ${ }^{13}$. Distant metastases are present at diagnosis in about one third of patients. Common sites of metastases are lung, local lymph nodes, intrathoracic lymph nodes, liver, and brain ${ }^{13}$. Surgery is the cornerstone of management in ATC and is associated with longer overall survival (OS) and progression-free survival (PFS) in stages IVA and IVB. Types of surgery include total thyroidectomy with or without neck dissection, subtotal thyroidectomy, hemithyroidectomy, and debulking 14, 15. Surgery is followed by adjuvant radiotherapy (RT) and/or chemotherapy for favorable results $4,11,14$. The local tumor extent and the general condition of the patient determine the surgical strategy. A good rule of thumb is that stage IVA or stage IVB disease in which grossly negative margins (R1) can be obtained should have a complete resection because it is associated with improved PFS and OS ${ }^{1,}{ }^{16}$. Complete resection is possible in approximately one-third of patients at presentation. The role of RT in the treatment of ATC has evolved from conventional high dose to altered fractionation RT such as hypofractionation and hyperfractionation based on the rapid doubling time and the relative radioresistance of ATC to a total dose of 45-66 Gy. The radiation treatment volume can 
be quite large due to the extrathyroid extension leading to significant morbidity especially when concurrent chemotherapy is given. The hyperfractionated regimen had a trend towards longer survival. 3-D Conformal RT (3DCRT) or Intensity Modulated RT (IMRT) did not affect survival or toxicity ${ }^{17}$. The total RT dose seems to be an important prognostic factor, as found by Swaak-Kragten et al where the median OS was 5.4 months for patients treated with a total dose > 40 Gy versus only 1.7 months with doses < 40 Gy ${ }^{18}$. In their study, Glaser et al showed that survival is better with a RT dose $>59.4$ Gy and that RT is a prognostic factor ${ }^{19}$. The treatment induced significant toxicity must be carefully weighted with the patient's performance, treatment goals, and overall prognosis 5 .

Due to the poor prognosis, ATC is treated with multimodality treatment. Some studies showed that multimodality treatment improved the 1-year survival to $70 \%$ for stages IVA and resectable stage IVB disease, improved 2- year survival of $60 \%$, and $50 \%$ surviving more than 2.5 years with a median survival of 5 years 20 , ${ }^{21}$. However, ATC has an extremely low cure rate even with the very best treatment which is mostly palliative ${ }^{22,}$ 23 .

The prognostic factors of ATC are derived from retrospective studies. Sugitani et al identified age and limited tumor size which is associated with higher tumor resectability as prognostic variables ${ }^{24}$. Liu et al reported that tumor size $<4 \mathrm{~cm}$, distant spread, surgical resection, RT and residual tumor were independent factors of prognosis of ATC patients who underwent treatment ${ }^{16}$. A large, multicenter Japanese study also identified age $\geq$ 70 years, presence of acute symptoms, leucocytosis, tumor size $>5 \mathrm{~cm}$, T4B tumor, and distant metastasis as poor prognostic indicators of survival.

We aimed to retrospectively study the treatment outcome and prognostic factors of ATC patients treated at our institution.

\section{METHODS}

We retrospectively examined the charts of 30 patients with confirmed diagnosed of ATC treated at the Clinical Oncology Department, Ain-Shams University between 2006 and 2017. The treatment protocol of ATC at our department follows that of the American Thyroid Association ATA. The charts of $3 / 30$ patients had incomplete data. The work-up included Computed tomography of the neck and chest and routine blood work. Computed tomography of the abdomen was performed in $2 / 30$ of the patients where it showed liver metastases. The American Joint Committee on Cancer staging manual ( $7^{\text {th }}$ edition) was used for TNM staging 25 .

Surgery was the first type of treatment in most of the patients. Types of surgery included debulking, total thyroidectomy with neck dissection when possible, and subtotal thyroidectomy. Post-operative external beam RT was administered in some of the patients. The RT volume included the anterior half of the neck and upper $5 \mathrm{~cm}$ of the mediastinum. The patients were planned using 2-D or 3-D planning system. Conventional fractionation was used and the total dose was 50 to 66
Gy over 5 weeks. Chemotherapy was given alone (as single agent or combined regimen) or before RT or surgery. The commonly used drugs based on the American Thyroid Association guidelines summary of trials were doxorubicin, cisplatin, carboplatin, dacarbazine, and paclitaxel ${ }^{10}$. The Response Evaluation Criteria in Solid Tumors (RECIST) criteria were used to assess response. The Eastern Cooperative Oncology Group (ECOG) performance scale was used to assess performance status at presentation.

The Statistical Package for Social Science (IBM SPSS) version 20 was used for statistical analysis. Overall survival was calculated from the date of diagnosis, which is the date of biopsy until the date of death or last follow-up. Kaplan-Meier was used to determine the survival distribution of patients and the statistical significance of differences was evaluated using the log-rank test. Cox regression analysis was used to study the effect of clinical factors and different treatment modalities on survival. The confidence interval was set to $95 \%$ and the margin of error accepted was set to $5 \%$. So, the $p$-value was considered significant if < 0.05 .

\section{RESULTS}

The clinical characteristics of the patients are summarized in table 1. To make a histopathological diagnosis, fine needle aspiration biopsy was performed in $22(73.3 \%)$ patients and true cut biopsy in $8(26.7 \%)$. There were more male than female patients $(2: 1$ ratio) and the mean age of all patients was 56 years. Only one patient had history of well differentiated thyroid carcinoma. At presentation, 10 (33.3\%) patients presented with lung metastases and $2(6.7 \%)$ with liver metastases.

Twenty-two $(73.3 \%)$ patients received at least one form of treatment (table 2). Eleven $(36.7 \%$ ) patients received single modality treatment and an equal number received combined modality treatment. Five patients did not receive treatment due to sudden death as a result of carotid artery invasion, refusal of treatment, stroke, and respiratory failure. Three patients had incomplete file data. Surgery was performed in 14 (46.7\%) patients. Total and subtotal thyroidectomies with or without neck dissection was done in $9(64.3 \%)$ of these 14 patients.

Fourteen $(46.7 \%)$ patients received RT including postoperative adjuvant RT in 8 patients, definitive RT in 5 , and definitive RT combined with chemotherapy in 1. The 2-D RT total dose ranged from 40 to $50 \mathrm{~Gy}$ in 6 (42.9\%) of them and the 3-D RT dose from 60 to $66 \mathrm{~Gy}$ in $8(57.1 \%)$. Thirteen $(43.3 \%)$ patients refused or discontinued RT due to deteriorating condition or death.

Chemotherapy was given to 7 patients as follows; single modality palliative chemotherapy in 2 stage IVC patients, combined surgery and chemotherapy in 2 stage IVC patients, combined surgery, chemotherapy and radiotherapy in 2 patients, and as a radiosensitizer (adriamycin) in 1 stage IVA patient. Combined chemotherapy regimens included doxorubicin / dacarbazine and taxol / carboplatin. Number of cycles ranged from 4 to 6 cycles. Chemotherapy was the main 
treatment of metastatic ATC whether as a single modality or combined with surgery.

Table 3 shows summary of treatment by stage of ATC.

Table 1: Patient characteristics $(n=30)$

\begin{tabular}{|c|c|}
\hline Variable & $n(\%)$ \\
\hline \multicolumn{2}{|l|}{ Age } \\
\hline Median (IQR) Range & $60(21-80)$ \\
\hline \multicolumn{2}{|l|}{ Sex } \\
\hline Female & $11(36.7)$ \\
\hline Male & $19(63.3)$ \\
\hline \multicolumn{2}{|l|}{ ECOG performance } \\
\hline 1 & $26(86.7)$ \\
\hline 2 & $4(13.3)$ \\
\hline \multicolumn{2}{|l|}{ Pathology } \\
\hline Anaplastic & $26(86.7)$ \\
\hline Poorly differentiated & $4(13.3)$ \\
\hline \multicolumn{2}{|l|}{ T stage } \\
\hline $\mathrm{T} 4 \mathrm{a}$ & $19(63.3)$ \\
\hline $\mathrm{T} 4 \mathrm{~b}$ & $11(36.7)$ \\
\hline \multicolumn{2}{|l|}{ N stage } \\
\hline N 0 & $16(53.3)$ \\
\hline $\mathrm{N} \mathrm{1a}$ & $5(16.7)$ \\
\hline $\mathrm{N} 1 \mathrm{~b}$ & $9(30)$ \\
\hline \multicolumn{2}{|l|}{ M stage } \\
\hline $\mathrm{M} 0$ & $18(60)$ \\
\hline M 1 & $12(40)$ \\
\hline \multicolumn{2}{|l|}{ Site of metastases } \\
\hline Liver & $2(6.7)$ \\
\hline Lung & $10(33.3)$ \\
\hline \multicolumn{2}{|l|}{ Stage } \\
\hline IV A & $14(46.7)$ \\
\hline IV B & $4(13.3)$ \\
\hline IV C & $12(40)$ \\
\hline \multicolumn{2}{|l|}{ Strap muscle invasion } \\
\hline No & $26(86.7)$ \\
\hline Yes & $4(13.3)$ \\
\hline \multicolumn{2}{|c|}{ Recurrent laryngeal invasion } \\
\hline Unknown & $2(6.7)$ \\
\hline No & $21(70)$ \\
\hline Yes & $7(23.3)$ \\
\hline \multicolumn{2}{|l|}{ Tracheal invasion } \\
\hline Unknown & $2(6.7)$ \\
\hline No & $23(76.7)$ \\
\hline Yes & $5(16.7)$ \\
\hline \multicolumn{2}{|l|}{ Esophageal invasion } \\
\hline Unknown & $2(6.7)$ \\
\hline No & $28(93.3)$ \\
\hline \multicolumn{2}{|l|}{ Tracheotomy } \\
\hline Unknown & $2(6.7)$ \\
\hline No & $17(56.7)$ \\
\hline Yes & $11(36.7)$ \\
\hline
\end{tabular}

By the end of treatment, 19 patients achieved partial response (PR), while the disease progressed in 3. During follow-up, $2(6.7 \%)$ stage IVA patients who achieved PR for 3 months then became metastatic to the lung, had tracheostomy and were kept on best supportive care due to the poor performance status. After a median follow-up duration of 3 months, the median OS was 3 months (95\% Confidence Interval: 1.43-4.57) (figure 1 a). By the end of the study, $20(66.7 \%)$ patients died due to the disease.
Table 2: Treatment and outcome of 30 patients with anaplastic thyroid carcinoma

\begin{tabular}{|c|c|}
\hline & $n(\%)$ \\
\hline \multicolumn{2}{|l|}{ Treatment plan } \\
\hline Single modality & $11(36.7)$ \\
\hline RT & $5(16.6)$ \\
\hline Surgery & $4(13.3)$ \\
\hline $\mathrm{CTH}$ & $2(6.7)$ \\
\hline Combined modality & $11(36.7)$ \\
\hline Surgery + RT & $6(20)$ \\
\hline Surgery + CTH & $2(6.7)$ \\
\hline Surgery + RT + CTH & $2(6.7)$ \\
\hline $\mathrm{RT}+\mathrm{CTH}$ & $1(3.3)$ \\
\hline No treatment received & $5(16.6)$ \\
\hline Unknown & $3(10)$ \\
\hline \multicolumn{2}{|l|}{ Treatment details } \\
\hline \multicolumn{2}{|l|}{ Surgery } \\
\hline Total thyroidectomy with ND & $4(13.3)$ \\
\hline Total thyroidectomy without ND & $2(6.7)$ \\
\hline Subtotal thyroidectomy & $3(10)$ \\
\hline Hemithyroidectomy without ND & $2(6.7)$ \\
\hline Hemithyroidectomy with SLND & $2(6.7)$ \\
\hline Debulking & $1(3.3)$ \\
\hline None & $16(53.3)$ \\
\hline \multicolumn{2}{|l|}{ Radiotherapy } \\
\hline Adjuvant & $8(26.7)$ \\
\hline Definitive & $6(20)$ \\
\hline None & $13(43.3)$ \\
\hline Unknown & $3(10)$ \\
\hline \multicolumn{2}{|l|}{ Chemotherapy } \\
\hline Yes & $7(23.3)$ \\
\hline None & $20(66.7)$ \\
\hline Unknown & $3(10)$ \\
\hline \multicolumn{2}{|l|}{ Response to treatment } \\
\hline Partial response & $19(63.3)$ \\
\hline Progression & $3(10)$ \\
\hline No treatment received & $5(16.7)$ \\
\hline Unknown & $3(10)$ \\
\hline \multicolumn{2}{|l|}{ Status at last follow-up } \\
\hline Alive & $10(33.3)$ \\
\hline Dead & $20(66.7)$ \\
\hline
\end{tabular}

RT: radiotherapy; CTH: chemotherapy; ND: neck dissection

In univariate analysis, male sex, stage IVA disease, surgery, RT and combined modality treatment plan were significantly associated with better OS (table 4 and figures $1 \mathrm{~b}-\mathrm{f})$. However, only female sex was identified as significant poor prognostic variable of OS $(P=0.043)$ by multivariate analysis (table 4 ).

\section{DISCUSSION}

Anaplastic thyroid carcinoma is a lethal disease with an OS of around 6 to 8 months. To date, most of data about this "orphan disease" has been obtained from single-institution studies with limited numbers of patients ${ }^{26}$. Due to its rarity and heterogeneity, it is difficult to draw conclusion for definitive treatment strategies ${ }^{27}$. The current standard of care for these patients is largely multimodal and palliative ${ }^{5}$.

This study presented the treatment outcome and prognosis of ATC patients at a single Egyptian institution. The patients and tumor had similar 
Table 3: Summary of treatment by stage for the 22 treated anaplastic thyroid cancer patients

\begin{tabular}{lllllll}
\hline Stage & Total & \multicolumn{2}{c}{ Treatment plan } & \multicolumn{2}{c}{ Treatment type } \\
\cline { 2 - 7 } & & Single modality & Combined modality & Surgery & Radiotherapy & Chemotherapy \\
\cline { 2 - 7 } & & \multicolumn{7}{c}{$\boldsymbol{n}(\boldsymbol{\%})$} \\
\hline Stage IVA & $14(46.7)$ & $5(16.7)$ & $5(16.7)$ & $5(16.7)$ & $10(33.3)$ & $1(3.3)$ \\
\hline Stage IVB & $4(13.3)$ & 0 & $2(6.7)$ & $2(6.7)$ & $2(6.7)$ & 0 \\
\hline Stage IVC & $12(40)$ & $6(20)$ & $4(13.3)$ & $7(23.3)$ & $2(6.7)$ & $6(20)$ \\
\hline
\end{tabular}

Table 4: Univariate and multivariate analysis of factors affecting overall survival

\begin{tabular}{|c|c|c|c|c|c|c|c|c|}
\hline \multirow[t]{2}{*}{ Variable } & \multirow[t]{2}{*}{$n$} & \multicolumn{2}{|c|}{ Overall survival (months) } & \multicolumn{2}{|c|}{ Log rank test } & \multicolumn{3}{|c|}{ Cox regression analysis } \\
\hline & & Median & $95 \% \mathrm{CI}$ & $\chi^{2}$ & $p$ value & HR & $95 \% \mathrm{CI}$ & $p$ value \\
\hline \multicolumn{9}{|l|}{ Age } \\
\hline$<60$ years & 14 & 2 & $0.167-3.833$ & \multirow[t]{2}{*}{1.288} & \multirow[t]{2}{*}{0.257} & & & \\
\hline$>60$ years & 16 & 4 & $1.075-6.925$ & & & & & \\
\hline \multicolumn{9}{|l|}{ Sex } \\
\hline Females & 11 & 1.5 & $0.421-2.579$ & \multirow[t]{2}{*}{4.235} & \multirow[t]{2}{*}{0.040} & 5.694 & $1.059-30.6$ & 0.043 \\
\hline Males & 19 & 4 & $1.65-6.35$ & & & Ref & & \\
\hline \multicolumn{9}{|c|}{ Laryngeal invasion } \\
\hline Yes & 23 & 4 & $2.326-5.674$ & \multirow[t]{2}{*}{1.543} & \multirow[t]{2}{*}{0.214} & & & \\
\hline No & 7 & 3 & $0-7.102$ & & & & & \\
\hline \multicolumn{9}{|c|}{ Tracheal invasion } \\
\hline No & 25 & 3 & $1.569-4.431$ & \multirow[t]{2}{*}{0.000} & \multirow[t]{2}{*}{0.995} & & & \\
\hline Yes & 5 & 4 & $2.236-5.764$ & & & & & \\
\hline \multicolumn{9}{|l|}{ Stage } \\
\hline IVA & 14 & 5 & $1.344-2.733$ & \multirow[t]{3}{*}{8.851} & \multirow[t]{3}{*}{0.012} & Ref & & \\
\hline IVB & 4 & 4.8 & $3.546-5.581$ & & & 0 & 0 & 0.981 \\
\hline IVC & 12 & 1.5 & $2.62-4.246$ & & & 2.097 & $0.337-13.069$ & 0.428 \\
\hline \multicolumn{9}{|l|}{ Surgery } \\
\hline No & 16 & 2.8 & $1.967-3.646$ & \multirow[t]{2}{*}{4.477} & \multirow[t]{2}{*}{0.034} & Ref & & \\
\hline Yes & 14 & 4.2 & $3.074-5.319$ & & & 0.659 & $0.128-3.389$ & 0.618 \\
\hline \multicolumn{9}{|l|}{ Radiotherapy } \\
\hline No & 13 & 2 & $1.344-2.733$ & \multirow[t]{2}{*}{8.910} & \multirow[t]{2}{*}{0.003} & Ref & & \\
\hline Yes & 14 & 4.5 & $3.546-5.581$ & & & 0.263 & $0.019-3.555$ & 0.315 \\
\hline \multicolumn{9}{|l|}{ Chemotherapy } \\
\hline No & 20 & 1.5 & $0-5.109$ & \multirow[t]{2}{*}{0.009} & \multirow[t]{2}{*}{0.925} & & & \\
\hline Yes & 7 & 3 & $2.145-3.855$ & & & & & \\
\hline Treatment moc & & & & & & & & \\
\hline Combined & 11 & NR & NR & 10.714 & 0.005 & Ref & & \\
\hline Single & 11 & 1.5 & $0-3.118$ & & & 1.662 & $0.211-13.079$ & 0.629 \\
\hline None & 5 & 1 & NR & & & 13.945 & $0.684-284.47$ & 0.087 \\
\hline
\end{tabular}

CI: Confidence interval; HR: Hazard ratio; NR: Not reached

characteristics to what is described in the literature. ATC is a disease of the elderly. The median age of the patients was 60 years less than the median age 69 years reported by Lim et al study ${ }^{26}$. Although most of the series demonstrated female predominance 1, 4, 22, our study reflected more male patients similar to reports by Lowe et al ${ }^{28}$ and Remick et al ${ }^{29}$ which documented high male to female patients' ratio. Female gender was identified by Roche et al as a poor prognostic factor ${ }^{30}$. In agreement, we demonstrated better survival of males compared to females $(p=0.043)$.

Although we believe that it is necessary to have tumor tissue for the correct identification of ATC, most of the patients $(73.3 \%)$ had a fine needle aspiration biopsy to make a diagnosis. Us-Krasoveck et al reported 113 patients with ATC; 107 (94.7\%) of them were diagnosed by fine needle aspiration biopsy, and 96 out of these 107 patients were correctly diagnosed as anaplastic cancer $^{31}$.

One of the features of ATC is the aggressive invasion of the thyroid capsule, adjacent structures, early lymph nodes and distant spread. In this study, there was a small number of patients with invaded recurrent laryngeal nerve (5/30 patients), trachea (5/30 patients), and strap muscles (4/30 patients), contrary to Liu et al where $31 / 50$ patients had invasion of the surrounding structures ${ }^{16}$. The incidence of metastases at presentation was $40 \%$ which is less than that in the study by Aslan et al $(55 \%, 16 / 29)$ where 8 patients presented with metastases and 8 patients developed it shortly after ${ }^{27}$. Our incidence of metastases was also lower than that reported by Venkatesh et al (53\%) who included a larger number of patients $(n=121)^{32}$. The lung was most common site of metastases $(30 \%)$ similar to McIver et al study $(42 \%)^{22}$.

Stage IVA represents around $2-15 \%$ of ATC; however, in our study it was the most common stage $(46.7 \%)$. Total thyroidectomy with a central and lateral neck dissection is recommended in both stages IVA and IVB disease. Preoperative RT may be used to downstage locally unresectable tumor to allow complete gross resection. In stage IVC ATC palliative resection is 


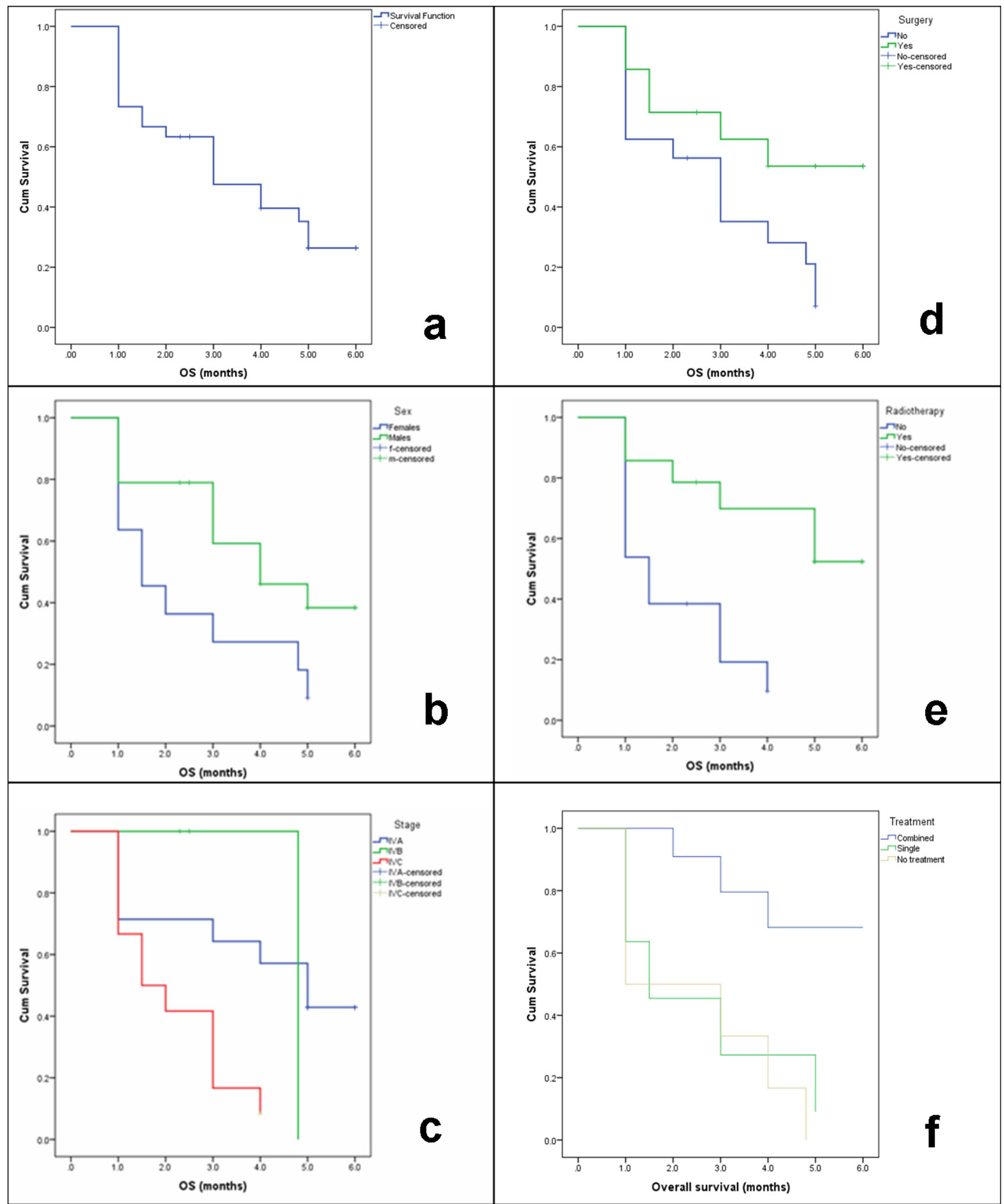

Figure 1: Overall survival according to: a) whole group, b) sex, c) stage d) surgery e) radiotherapy, and f) treatment modality approach (single vs. combined)

performed if possible ${ }^{33}$. The significance of surgical resection is controversial since most ATC patients are unresectable at diagnosis; that is why it is difficult to assess the benefits of surgical resection without introducing selection bias ${ }^{22}$. However, most studies reported that curative resection significantly affected survival $4,14,22,34$. In accordance, we demonstrated that surgery significantly improved survival ( $p=0.034$ ) only by univariate analysis. Pierie et al treated 44 out of 67 ATC patients surgically and reported 1 and 3 year OS rates of $92 \%$ and $83 \%$, respectively after complete resection; $35 \%$ and $0 \%$, respectively, after debulking; and $4 \%$ and $0 \%$, respectively, after no resection ${ }^{35}$. In the current study surgery was carried out in $46.7 \%$ of the patients whether 
as single treatment or combined with other modality. The most common type of surgery was subtotal thyroidectomy followed by total thyroidectomy with node dissection and debulking.

Radiotherapy should be initiated urgently after securing and maintaining patent upper airway, usually within 2-3 weeks after surgery due to the rapid recurrence after surgery ${ }^{5}$. Radiotherapy is a part of potentially curative (stages IVA and IVB) or palliative intent (stage IVC) multimodality treatment and is associated with good local control. Bahtia et al reported the outcome of 31 ATC patients treated with curative intent 3DCRT or IMRT combined with chemotherapy ${ }^{36}$. For the whole group, the median dose was 55 Gy (range 4-70 GY) and for the 13 patients who were irradiated using IMRT it was $60 \mathrm{~Gy}$ (range 39.9-69.0 Gy). The 1- year OS was 29\% for definitively irradiated patients. The authors concluded that doses > 50 Gy if tolerated lead to better outcomes since there is no standard RT dose. Half of our cohort received RT as a single modality, as an adjuvant following surgery or in combination with chemotherapy as a radiosensitizer. We used dose ranges similar to the literature, total dose 4050 Gy for 2-D RT and 60-66 Gy for 3DCRT. We found that RT significantly improved OS by univariate analysis $(p=0.003)$, but this was not confirmed by multivariate analysis. In agreement with our results, Aslan et al confirmed that RT with or without chemotherapy, improved survival $(p=0.04)^{27}$. The authors also showed that postoperative RT dose $>33.1$ Gy led to better survival $(p=0.04)$. Liu et al recommended postoperative RT doses of 40 Gy in stage IVA and IVB disease and also palliative doses in stage IVC to improve the quality of life ${ }^{16}$. Toxicity can be a limiting factor with RT because concurrent chemotherapy is often used, and the large RT volume that includes a significant part of the larynx and cervical esophagus ${ }^{5}$. Kim and Leeper observed high incidence of pharyngoesophagitis and tracheitis in their series ${ }^{17}$. Wong et al also reported skin changes, esophageal toxicity, and radiation myelopathy ${ }^{37}$. We did not look at treatment toxicity in this study.

Anaplastic thyroid carcinoma is not a very chemosensitive tumor. It is controversial whether chemotherapy can prolong the survival time and improve prognosis ${ }^{38}$. Chemotherapy has been studied in small retrospective studies in the neoadjuvant setting to downstage unresectable tumors ${ }^{39}$. In the series by Higashiyama et al, 9 patients with stage IVB received neoadjuvant weekly paclitaxel and had a response rate of $33 \%{ }^{38}$. Four patients became amenable to curative intent surgery and adjuvant therapy and were alive and disease free at 32 months. Adjuvant chemotherapy as a single modality is of uncertain benefit; however adjuvant chemotherapy with RT is effective for obtaining favorable outcomes ${ }^{4,14}$. Similar to adjuvant RT, adjuvant chemotherapy should be started within 2-3 weeks after surgery ${ }^{6}$. In patients with non-metastatic ATC with good performance status adjuvant chemotherapy should be added to RT after R0 or R1 thyroidectomy but at the expense of increased toxicity ${ }^{4}$, 14. Kumar et al studied the multimodal aggressive approach to ATC, which included R0 and/or R1 performed in the majority of patients, followed by radiosensitizing chemotherapy administered with 66 Gy IMRT ${ }^{39}$. The radiosensitizing chemotherapy was continued as adjuvant chemotherapy for as long as tolerated by the patients. The median OS was 22.4 months for the entire cohort which consisted mostly of stage IVB disease. Doxorubicin is the most widely used agent as a radiosensitizer. Doxorubicin in a weekly low dose administered as radiosensitizer had a 2-year local control rate of $68 \%$ and median survival time of 1 year 40. In advanced stage IVC anaplastic thyroid carcinoma no chemotherapy or targeted therapy has been shown to be potentially curative or to improve survival rates ${ }^{39}$. Taxanes, doxorubicin, and platins have shown activity as a single or combined agents with response rates ranging from $15 \%$ to $25 \%$ 41. The combined RT and chemotherapy regimens with doxorubicin with or without taxanes or cisplatin combined with RT have shown the most promising results ${ }^{19,42}$. In the current study, chemotherapy was administered to few patients $(n=7)$ and did not influence OS. Chemotherapy was mainly administered to patients with stage IVC (as a single definitive treatment in 2 patients and as a combined modality in 4) who all achieved PR except for one patient who had disease progression, while only one stage IVA patient developed PR. Single agents included doxorubicin or dacarbazine, while combination chemotherapy regimens included taxol/carboplatin or doxorubicin/dacarbazine for 4-6 cycles. The impact of single-modality palliative chemotherapy on survival of patients with stage IVC is unclear.

Multimodality treatment is the current standard treatment of ATC due to its aggressive nature. Multimodality treatment was not a prognostic factor in the study by Kihara et $\mathrm{al}^{43}$ and McIver et $\mathrm{al}^{22}$. Similarly, in the present study multimodality treatment improved the OS by univariate analysis $(p=0.005)$, but not with multivariate analysis. Our results were in contrast to De Crevoisier et al ${ }^{44}$ who treated 30 patients with ATC with combined modality therapy resulting in 1-year survival of $46 \%$ and a 3 -year survival of $27 \%$, which was slightly better than results of most other studies. Lim et al retrospectively reviewed medical records of 13 ATC patients treated with multimodality therapy ${ }^{26}$. The median PFS was 2.8 months, and the median OS was 3.8 months similar to our survival results. Our data agree with the literature where the OS of combined modality was 4.2 months, compared to single modality which resulted in OS of 2.5 months. None of our patients completed one year survival due to the relatively large number of stage IVC patients at presentation in addition to the 2 patients who developed distant metastases later on.

The median OS reported in the current study was 3 months which is less than the 3.9 months median OS of 100 patients reported by Akaishi et al ${ }^{12}$, but similar to the 2.8 median OS of 13 patients studied by Lim et al ${ }^{26}$. Several studies have examined the factors affecting prognosis in patients with ATC. The prognostic factors include patient age, tumor size, and clinical stage which should be considered when evaluating patients for treatment ${ }^{12}$. Univariate and multivariate analyses of factors affecting survival by Kihara et al showed that 
complete surgery was an independent prognostic factor $^{43}$. Other reports also found that complete resection was associated with longer survival compared to incomplete surgery or biopsy ${ }^{14,16}$. Sun et al reported on treatment and prognosis of 60 patients diagnosed with ATC ${ }^{14}$. Univariate analysis revealed that age, white blood cell count, platelet count, distant metastases, clinical stage, chemotherapy, RT, and therapeutic regimen significantly affected the prognosis of patients with ATC, while surgery did not influence survival. Multivariate analysis, identified white blood cell count, surgery, and post-operative RT as independent prognostic factors in ATC patients. According to Glaser et al, age and tumor size may be prognostic factors in ATC patients ${ }^{19}$. Our results did not identify sex, stage, surgery or RT as significant predictors of survival by multivariate analysis.

New clinical trials investigate the role of targeted therapy to improve the survival rates or quality of life of advanced ATC patients. Molecular targeted therapy trials in ATC have studied BRAF-directed agents, mTOR inhibitors, multikinase inhibitors (MKIs). Sorafenib is a MKI approved by the United States Food and Drug Administration (FDA) for advanced thyroid cancer ${ }^{45}$. Lenvatinib is currently approved for treatment of differentiated thyroid cancer in the United States and is approved for all subtypes of thyroid cancer in Japan ${ }^{5}$.

\section{Conclusion}

Our findings agree with the literature as regards the characteristics of patients, prognostic factors, type of treatment and its outcome. To the best of our knowledge this is the only report on anaplastic thyroid carcinoma from Egypt. We identified sex as one of the important factors influencing survival, but we could not confirm the role of stage, surgery, and multiple modality treatment in improving OS. To date, in stages IVA and IVB multimodality treatment improves local control and appears to achieve better survival outcome. In stage IVC extensive surgical resections do not improve survival, and priority should be given to quality of life. These patients should be offered enrollment in clinical trials whenever possible.

\section{Conflict of interest}

None to declare

\section{REFERENCES}

1. Kebebew E, Greenspan FS, Clark OH, Woeber KA, McMillan A. Anaplastic thyroid carcinoma. Treatment outcome and prognostic factors. Cancer. 2005; 103(7):1330-1335

2. Are C, Shaha AR. Anaplastic thyroid carcinoma: biology, pathogenesis, prognostic factors, and treatment approaches. Ann Surg Oncol. 2006; 13(4): 453-464.

3. Kebebew E. Anaplastic thyroid cancer: rare, fatal, and neglected. Surgery. 2012; 152(6): 1088-1089.

4. Haigh PI, Ituarte PH, Wu HS, et al. Completely resected anaplastic thyroid carcinoma combined with adjuvant chemotherapy and irradiation is associated with prolonged survival. Cancer. 2001; 91(12): 2335-2342.

5. Cabanillas ME, Zafereo M, Gunn GB, Ferrarotto R. Anaplastic Thyroid Carcinoma: Treatment in the Age of
Molecular Targeted Therapy. J Oncol Pract. 2016; 12(6): 511-518.

6. Smallridge RC, Copland JA. Anaplastic thyroid carcinoma: pathogenesis and emerging therapies. Clin Oncol (R Coll Radiol). 2010; 22(6): 486-497.

7. O'Neill JP, Shaha AR. Anaplastic thyroid cancer. Oral Oncol. 2013; 49(7): 702-706.

8. Charles RP, Silva J, Iezza G, Philips WA, McMahon M. Activating BRAF and PIK3CA mutations cooperate to promote anaplastic thyroid carcinogenesis. Mol Cancer Res. 2014; 12(7): 979-986.

9. Pita JM, Figueiredo IF, Moura MM, Leite V, Cavaco BM. Cell cycle deregulation and TP53 and RAS mutations are major events in poorly differentiated and undifferentiated thyroid carcinomas. J Clin Endocrinol Metab. 2014; 99(3): E497-507.

10. Smallridge RC, Ain KB, Asa SL, et al. American Thyroid Association guidelines for management of patients with anaplastic thyroid cancer. Thyroid. 2012; 22(11): 11041139.

11. Foote RL, Molina JR, Kasperbauer JL, et al. Enhanced survival in locoregionally confined anaplastic thyroid carcinoma: a single-institution experience using aggressive multimodal therapy. Thyroid. 2011; 21(1): 2530 .

12. Akaishi J, Sugino K, Kitagawa W, et al. Prognostic factors and treatment outcomes of 100 cases of anaplastic thyroid carcinoma. Thyroid. 2011; 21(11): 1183-1189.

13. Abate EG, Smallridge RC. Unraveling the best combination of therapies to treat anaplastic thyroid cancer. Editorial. Expert Rev Endocrinol Metab. 2016; 11 (3): 235-237.

14. Sun $\mathrm{C}, \mathrm{Li} \mathrm{Q}, \mathrm{Hu} \mathrm{Z}$, et al. Treatment and prognosis of anaplastic thyroid carcinoma: experience from a single institution in China. PLoS ONE. 2013, 8(11): e80011.

15. Keutgen XM, Sadowski SM, Kebebew E. Management of anaplastic thyroid cancer. Gland Surg. 2015; 4(1):44-51.

16. Liu TR, Xiao ZW, Xu HN, et al. Treatment and prognosis of anaplastic thyroid carcinoma: a clinical study of 50 cases. PLoS One. 2016; 11(10): e0164840.

17. Kim JH, Leeper RD. Treatment of locally advanced thyroid carcinoma with combination doxorubicin and radiation therapy. Cancer. 1987; 60(10): 2372-2375.

18. Swaak-Kragten AT, de Wilt JH, Schmitz PI, Bontenbal M, Levendag PC. Multimodality treatment for anaplastic thyroid carcinoma: treatment outcome in 75 patients. Radiother Oncol. 2009; 92(1): 100-104.

19. Glaser SM, Mandish SF, Gill BS, Balasubramani GK, Clump DA, Beriwal S. Anaplastic thyroid cancer: Prognostic factors, patterns of care, and overall survival. Head Neck. 2016; 38 (Suppl 1): E2083-2090.

20. Ito K, Hanamura T, Murayama $\mathrm{K}$, et al. Multimodality therapeutic outcomes in anaplastic thyroid carcinoma: improved survival in subgroups of patients with localized primary tumors. Head Neck. 2012; 34(2): 230-237.

21. McLarnon A. Thyroid cancer: Pazopanib alone is not effective against anaplastic thyroid cancer. Nat Rev Endocrinol. 2012; 8(10): 565.

22. McIver B, Hay ID, Giuffrida DF, et al. Anaplastic thyroid carcinoma: a 50-year experience at a single institution. Surgery. 2001; 130(6): 1028-1034.

23. Lo CY, Lam KY, Wan KY. Anaplastic carcinoma of the thyroid. Am J Surg. 1999; 177(4): 337-339.

24. Sugitani I, Miyauchi A, Sugino K, Okamoto T, Yoshida A, Suzuki S. Prognostic factors and treatment outcomes for anaplastic thyroid carcinoma: ATC Research 
Consortium of Japan cohort study of 677 patients. World J Surg. 2012; 36(6): 1247-1254.

25. Edge SB, Byrd DR, Compton CC, Fritz AG, Greene FL, Trotti A. AJCC Cancer Staging Manual. $7^{\text {th }}$ Ed. New York, NY: Springer; 2010. pp: 87-96.

26. Lim SM, Shin SJ, Chung WY, et al. Treatment outcome of patients with anaplastic thyroid cancer: a single center experience. Yonsei Med J. 2012; 53(2): 352-357.

27. Aslan ZA, Granados-García M, Luna-Ortiz K, et al. Anaplastic thyroid cancer: multimodal treatment results. Ecancermedicalscience. 2014, 8: 449.

28. Lowe NM, Loughran S, Slevin NJ, Yap BK. Anaplastic thyroid cancer: the addition of systemic chemotherapy to radiotherapy led to an observed improvement in survival - a single centre experience and review of the literature. ScientificWorldJournal. 2014; 2014: 674583.

29. Nagaiah G, Hossain A, Mooney CJ, Parmentier J, Remick SC. Anaplastic thyroid cancer: a review of epidemiology, pathogenesis, and treatment. J Oncol, 2011; 2011: 542358.

30. Roche B, Larroumets G, Dejax C, et al., Epidemiology, clinical presentation, treatment and prognosis of a regional series of 26 anaplastic thyroid carcinomas (ATC). Comparison with the literature. Ann Endocrinol (Paris). 2010; (71)1: 38-45.

31. Us-Krasovec M, Golouh R, Auersperg M, Besic N, Ruparcic-Oblak L. Anaplastic thyroid carcinoma in fine needle aspirates. Acta Cytol. 1996; 40(5): 953-958.

32. Venkatesh YS, Ordonez NG, Schultz PN, Hickey RC, Geopfert H, Samaan NA. Anaplastic carcinoma of the thyroid. A clinicopathologic study of 121 cases. Cancer. 1990; 66(2): 321-330.

33. Chen J, Tward JD, Shrieve DC, Hitchcock YJ. Surgery and radiotherapy improve survival in patients with anaplastic thyroid carcinoma: analysis of the surveillance, epidemiology, and end results 1983-2002. Am J Clin Oncol. 2008; 31(5): 460-464.

34. Wang Y, Tsang R, Asa S, Dickson B, Arenovich T, Brierley J. Clinical outcome of anaplastic thyroid carcinoma treated with radiotherapy of once- and twicedaily fractionation regimens. Cancer. 2006; 107(8): 17861792.

35. Pierie JP, Muzikansky A, Gaz RD, Faquin WC, Ott MJ. The effect of surgery and radiotherapy on outcome of anaplastic thyroid carcinoma. Ann Surg Oncol. 2002; 9(1): 57-64.

36. Bhatia A, Rao A, Ang KK, et al. Anaplastic thyroid cancer: Clinical outcomes with conformal radiotherapy. Head Neck. 2010; 32(7): 829-836.

37. Wong CS, Van Dyk J, Simpson WJ. Myelopathy following hyperfractionated accelerated radiotherapy for anaplastic thyroid carcinoma. Radiother Oncol. 1991; 20(1): 3-9.

38. Higashiyama $\mathrm{T}$, Ito $\mathrm{Y}$, Hirokawa $\mathrm{M}$, et al. Induction chemotherapy with weekly paclitaxel administration for anaplastic thyroid carcinoma. Thyroid. 2010: 20(1): 7-14.

39. Kumar A, Prasongsook N, Kasperbauer J. Outcomes in response to aggressive multi-modal therapy in anaplastic thyroid cancer: The Mayo Clinic experience. Thyroid. 2015; 25 (suppl 1; abstr 72).

40. Pacini F, Vitti P, Martino E, et al. Treatment of refractory thyroid cancer with doxorubicin. Drugs Exp Clin Res.1984; 10(12): 911-914.

41. Sun XS, Sun SR, Guevara N, et al. Chemoradiation in anaplastic thyroid carcinomas. Crit Rev Oncol Hematol. 2013; 86(3): 290-301.

42. Chiacchio S, Lorenzoni A, Boni G, Rubello D, Elisei R, Mariani G. Anaplastic thyroid cancer: prevalence, diagnosis and treatment. Minerva Endocrinol. 2008; 33(4): 341-357.

43. Kihara M, Miyauchi A, Yamauchi A, Yokomise H. Prognostic factors of anaplastic thyroid carcinoma. Surg Today. 2004; 34(5):394-398.

44. De Crevoisier R, Baudin E, Bachelot A, et al. Combined treatment of anaplastic thyroid carcinoma with surgery, chemotherapy, and hyperfractionated accelerated external radiotherapy. Int J Radiat Oncol Biol Phys. 2004; 60(4):1137-1143.

45. Abdel-Rahman O, Fouad M. Risk of thyroid dysfunction in patients with solid tumors treated with VEGF receptor tyrosine kinase inhibitors: a critical literature review and meta-analysis. Expert Rev Anticancer Ther. 2014; 14(9): 1063-1073. 